\title{
COMMENT
}

\section{When the pie is too small}

\author{
Gregory A Petsko*
}

Thirty-two billion US dollars is a lot of money. It's more than the gross national product of Kuala Rokat, a nonexistent but real-sounding country. If it were in pennies the resulting stack of 3.2 trillion coins would be roughly 5 billion meters high, tall enough to reach from the surface of the earth roughly a tenth of the way to Mars. In one dollar bills, which don't weigh more than a gram, it would weigh about three times as much as the Eiffel Tower. Any way you express it, it's a mighty big pie. Unfortunately, it's not big enough.

The Congress of the United States is currently debating the budget for the National Institutes of Health $(\mathrm{NIH})$, the world's largest provider of research funding for biomedical science in general (and genome biology in particular), and $\$ 32$ billion is the figure they are currently recommending for fiscal year 2011. If that is the number ultimately awarded, the biomedical science research community in the US is going to face some agonizing choices.

Before the stimulus funding of 2009-2010, the NIH budget was $\$ 30$ billion. $\$ 32$ billion would represent an increase, but one substantially less than the level of scientific inflation, which has been averaging about $6 \%$ a year over the past few years. And the base budget was too small already back then, because of years of declining funding (in inflation-adjusted dollars) under George W Bush. The Federation of American Societies for Experimental Biology (FASEB) estimated that $\$ 37$ billion would be needed to bring the budget up to where it should be, and to avoid what some are calling a 'cliff' in funding as the $\$ 10$ billion in stimulus money that was added to the base budget last year runs out. My personal view was that we needed something as close to $\$ 40$ billion as we could get. $\$ 32$ billion isn't close at all.

Things could change before the final budget is passed, but I doubt it. Congress is scared to death about the burgeoning US deficit, which is stupid because we are in a deep recession with close to double-digit unemployment and a real interest rate close to zero. Keynesian

*Correspondence: petsko@brandeis.edu

Rosenstiel Basic Medical Sciences Research Center, Brandeis University, Waltham, MA 02454-9110, USA economics tells you that in such a situation, where monetary policy is useless because interest rates cannot go negative, the government should be spending more, not less. And spending money on scientific research is particularly smart, because it has been estimated that every dollar spent that way rapidly produces 2.0-2.5 dollars of economic output, one of the highest multipliers for any form of government investment. But the US Congress has been remarkably spineless of late, and in the face of calls for fiscal restraint by the political right, it seems unlikely that we will see an increase in the proposed amount for the NIH.

There's another reason not to expect much, and that's because the Democrats are in power. I know, it seems ridiculous that Barack Obama's administration, which actually respects science and listens to its advice, would leave biomedical research high and dry, but I think they will. Democratic administrations usually do. The problem isn't that they don't love science, it's that they love their favorite social programs more, and there simply isn't enough money to fund both at the level they are clamoring for. The odd thing about US politics (okay, one of many odd things) is that, with the exception of the anti-intellectual, science-phobic Bush administration, Republican governments have been friendlier to scientific research, in terms of funding, than their Democratic counterparts. Republicans have largely bought the idea that funding research, including 'basic' research, helps the competitiveness of the country and jump-starts new businesses. There will be a lot more money under Obama for energy research (the Democrats have completely accepted the idea that global warming is a huge problem), but that may well be at the expense of money for the life sciences.

What, then, does a $\$ 32$ billion NIH budget mean for American science? If present trends in funding priorities continue, it means that the number of individual investigator-initiated grants (called 'R01s' in NIH-speak) is going to shrink dramatically, as the bureaucrats in Washington use the precious dollars first to maintain and possibly expand - their pet big science programs. Keeping the cancer genome program and the structural genomics program and the genome-wide association studies afloat will require that the R01 pool shrink, and it is already, in percentage terms, dangerously low. 
Kyle Brown, public policy fellow at the American Society for Biochemistry and Molecular Biology, has put together some initial data that illustrate this looming crisis. Using the total number of R01s and investigators in a given year, he has calculated the average number of R01 grants per investigator from 1965 to 2005. The data were obtained from the NIH RePORT website (http:// report.nih.gov/index.aspx; specifically http://grants2.nih. gov/grants/new_investigators/New_Invest_Grants_and_ Numbers.xls).

In 2005, the average number of R01-equivalents per investigator was 1.35 . This average has climbed steadily since 1970, when it was 1.12, and its rate of increase has become steeper since the 7-year NIH budget doubling began in the late 1990s. One interpretation of this trend is that proportionally more principal investigators (PIs) are able to obtain more than one grant than they were in 1970. This trend accelerated during the doubling. Taking this further, it suggests that as the budget has increased, the NIH is putting more of its money into proportionally fewer labs.

The distribution of grants per investigator looks exponential and has a mode of 1 (the most investigators have one grant, the second most have two, the third most have three, and so on). But perhaps even more important is the dollar amount, because it is the finite pie that we're talking about here. During the past 10 years, a small number of laboratories and groups of laboratories have been receiving an increasing share of that pie, as big, expensive data-gathering projects and programs have increased at the expense of single-investigator hypothesisdriven research grants.

These numbers show why all scientists should fear for the R01 pool in a time of disastrously small budgets. I am not sanguine that most of the directors of the NIH institutes and centers, who control their individual budgets, are going to be able to resist the temptation to protect the most visible, glamorous, and disease-related work while letting the number of 'basic' science projects shrink. It is, therefore, incumbent on us to offer them solutions to the small-pie problem that keep that from happening. Here are some ways that have been suggested of cutting the pie into more slices, predicated on the assumption - which seems entirely reasonable to me that it is better to give an investigator with a good idea some money than no money at all.

(1) Impose a cap on the maximum dollar amount per R01 grant for direct and, more importantly, indirect costs. The former are the dollars that actually go to the investigator(s); the latter are the dollars that go to the institution to cover the costs of administering the grant. Indirect cost rates range from around 20\% of total direct costs to over $100 \%$ (and yes, that's not a typo), so a $\$ 1$ million grant spread over 5 years can actually end up costing the NIH $\$ 1.5$ million or more. The problem with this strategy is that most research universities, and medical schools in particular, live on indirect costs, and an abrupt shutoff of the pipeline could starve them.

(2) It may be necessary to make people with special longterm sources of funding, such as those with research chairs that supply large amounts of research dollars, or Investigators of the Howard Hughes Medical Institutes, ineligible for more than one R01 grant on top of their other funding. An exception could be made if they were in the 3-year transition period after being dropped as a Howard Hughes Investigator, or were about to lose the special funds for any reason. How to determine whether there is enough special funding to trigger such a restriction is not obvious to me.

(3) Impose a cap on the maximum number of R01 total dollars per PI. I have no idea how to set that figure fairly given the vastly different costs of clinical and non-clinical research, but maybe someone else will.

(4) Reduce the maximum duration of an R01 grant (currently 4-5 years) to perhaps 3-4 years. The burden this will place on scientists will be considerable, given that they already spend a huge percentage of their time writing grants now.

(5) Impose a limit of no more than one R01 equivalent per PI from any one NIH institute. That would have the advantage of forcing scientists to become more interdisciplinary, and the disadvantage of flooding, say, the National Cancer Institute with applications from people who know nothing about cancer.

(6) Award percentages of recommended budgets according to how highly a proposal was rated by the grants review panel. Thus, the top 5\% of proposals would receive $100 \%$ of their recommended (not requested) budget; the next $5 \%$ would receive $75 \%$, the next $5 \% 65 \%$, and the next $5 \% 50 \%$. This is the solution I prefer, as it rewards quality while stretching the research dollars to cover more investigators.

Any of these provisions would need to be reversible pending a better funding climate. Given the difficulty in ending any government program, that may be harder to carry out than the actual spending restrictions, which is another reason I prefer solution 6 above; it would have the least severe long-term consequences. The commitment for each institute and center could be to aim for a payline of, say, $20 \%$ of recommended R01 proposals receiving funding, which they would achieve by cutting and/or modifying spending using some combination of these provisions as necessary. (My friend John Kyriakis owlishly points out that the political climate is just right to get such ideas implemented. NIH could claim it is contributing to 'reducing big government') 
Of course, an even better solution would be to terminate some of the pie-hogging big science programs and put the savings into the R01 pool. That's what we should in fact do, so I guess there really isn't a hope in hell that we will.

By the way, $\$ 32$ billion is exactly the sum that BP has been forced to pay by the US government as a penalty for the Gulf of Mexico oil spill. I don't know whether to laugh at that coincidence or just cry.

Published: 30 July 2010

doi:10.1186/gb-2010-11-7-127

Cite this article as: Petsko GA: When the pie is too small. Genome Biology 2010, 11:127. 